\title{
Historicidade da participação e interação no jornalismo televisivo
}

Paulo Eduardo Silva Lins CAJAZEIRA ${ }^{1}$

\begin{abstract}
Resumo:
O presente trabalho se propõe a analisar a lógica de participação do público no telejornalismo brasileiro. Nessa perspectiva, o problema de pesquisa investiga em que medida os processos de interação no telejornal contribuem para participação efetiva do telespectador em espaços do telejornalismo. A investigação parte de dois experimentos empíricos: a) revisão bibliográfica dos processos de participação do público de 1950 até os anos $2010 ;$ b) aplicação de uma ficha de análise de cibermeio adaptada à interatividade no telejornalismo, a fim de verificar as formas de participação e interação do público no Jornal Nacional da TV Globo, um dos mais antigos telejornais em atividade no Brasil. Como resultado, verificou-se que a lógica de participação no site do Jornal Nacional funciona de acordo com um interessante sistema de convergência para as redes sociais. Na atualidade é um produto híbrido, concebido para várias mídias, e que fortalece sua atuação perante o público ao apresentar multiformatações disponíveis para multitelas.
\end{abstract}

Palavras-chave: Participação. Público do telejornalismo. Interatividade. Colaboração.

\section{Historicity of participation and interaction of television journalism}

\begin{abstract}
:
This work aims to analyze the logic of public participation in Brazilian television news. In this perspective, the research problem investigates the extent to which the processes of interaction in television news contribute to the effective participation of the viewer in spaces of television news. The investigation starts from two empirical experiments: a) bibliographic review of the processes of public participation from 1950 to the years 2010; b) application of a cybermedia analysis form adapted to interactivity in television news, in order to verify the forms of public participation and interaction in Jornal Nacional on TV Globo, one of the oldest television news programs in activity in Brazil. As a result, it was verified that the logic of participation in the Jornal Nacional website works in accordance with an interesting convergence system for social networks. Nowadays it is a hybrid product, designed for various media, and which strengthens its performance before the public by presenting multi-formatting available for multi-screens.
\end{abstract}

Keywords: Participation. TV journalism public. Interaction. Collaboration.

\footnotetext{
1 Doutor em Comunicação e Semiótica pela Pontifícia Universidade Católica de São Paulo. Professor Associado na Universidade Federal do Cariri, Ceará.E-mail: paulo.cajazeira@ufca.edu.br
} 


\title{
Historicidad de participación e interacción del periodismo televisivo
}

\begin{abstract}
Resumen:
Este trabajo tiene como objetivo analizar la lógica de la participación pública en las noticias de la televisión brasileña. En esta perspectiva, el problema de investigación investiga hasta qué punto los procesos de interacción en las noticias de televisión contribuyen a la participación efectiva del espectador en espacios de noticias de televisión. La investigación se basa en dos experimentos empíricos: a) revisión bibliográfica de los procesos de participación pública desde 1950 hasta 2010; b) la aplicación de un formulario de análisis de cibermedios adaptado a la interactividad en las noticias de televisión, para verificar las formas de participación e interacción del público en Jornal Nacional en TV Globo, uno de los programas de noticias de televisión más antiguos en actividad en Brasil. Como resultado, se verificó que la lógica de participación en el sitio web de Jornal Nacional funciona de acuerdo con un interesante sistema de convergencia para redes sociales. Hoy en día es un producto híbrido, diseñado para varios medios, y que fortalece su rendimiento ante el público al presentar formatos de pantallas múltiples.
\end{abstract}

Palabras clave: Participación. Periodismo televisivo público. Interacción. Colaboración.

\section{Introdução}

O objetivo principal deste estudo é analisar a lógica de participação do público no telejornalismo brasileiro. No dia 18 de setembro de 2020, a televisão brasileira comemora o seu $70^{\circ}$ aniversário de atuação ininterrupta no país. Para registrar o fato, este estudo objetiva verificar como o público participou e participa na construção do telejornalismo com sugestões, elogios, reclamações e conteúdos colaborativos desde os primórdios até a atualidade. Para tanto, devemos, primeiramente, conhecer os conceitos de audiência, público, massa e multidão, a fim de buscar identificar a representatividade coletiva do público do telejornal e as relações comunicacionais nesse espaço midiatizado, para, em seguida, investigar os processos de participação.

Conforme orienta o pesquisador Dayan (2006, p. 32), a distinção de audiência é uma situação "espinhosa", por motivos culturais. Em francês, por exemplo, a noção de público serve de termo genérico, e a noção de audiência apresenta-se como um termo conotado. Ou seja, um está sujeito ao outro. Já em inglês ocorre o contrário: a audiência serve de grau zero e o público corresponde à audiência particularizada.

Nesse sentido, a audiência é o que resta após ser estabelecido o público, os seus contornos gerais. Como afirma o autor (2006, p. 32), "um público constitui um meio", que supõe certo grau de sociabilidade e um mínimo de estabilidade. Essa sociabilidade do público depende de uma deliberação interna e uma capacidade de desempenho, 
performance. "A sua existência passa por uma capacidade de se auto imaginar, pelos modos de representação do coletivo, por ratificações de pertença" (DAYAN, 2006, p. 32). Já a audiência não se caracteriza por essa personificação, nem por uma obrigação de ser sociável e estável. A sua atuação responde a uma solicitação. Tal qual o público, a audiência se instala em uma realidade imaginada. O desafio é saber por quem o sujeito coletivo é imaginado para que exista.

Ao separar conceitualmente audiência e público de TV, verifica-se que ambos são compostos pelos mesmos telespectadores. Nas audiências de TV, pode-se esconder públicos. Considera-se que a transformação de audiência em público ocorre quando se verifica que a audiência, a todo instante, é conclamada pelo telejornal a assisti-lo: um ato comunicativo do enunciador em procurar medir a sua audiência ao direcioná-la à programação de TV.

Os telespectadores podem, no entanto, formar um público com visibilidade e romper o anonimato no período pós-massivo. Esse ato comunicativo do público em tornar-se um indivíduo participante denomina-se de "fuga do anonimato" (CAJAZEIRA, 2014 , p. 21). A televisão, como importante meio de comunicação de massa, fez a sociedade entender o mundo por meio das telas. A audiência na modernidade não se contenta mais em ter alguém a falar por si. Ele, público, quer fazer-se ouvir, e a era digital mostra-se o espaço ideal para o processo comunicativo.

Conforme Bauman (2001), existem dois modelos de visibilidade: o panóptico e o sinóptico, que se relacionam à mobilidade e ao sedentarismo. O sinóptico pode ser relacionado à mobilidade, e o panóptico, ao nomadismo. A televisão analógica estava até o início do século XXI no modelo de produção e recepção panóptico. Com a digitalização da mídia televisiva, altera-se para um modelo sinóptico, no qual o público participa, interfere e altera as formas de interação. Ao contrário do panóptico, em que há a necessidade de inserir os vigiados no espaço de observação, produzindo a certeza de que tudo é passível de vigilância e, consequentemente, de punição, no segundo modelo, o sinóptico, o ato de vigiar desprende os vigilantes de sua localidade, não importando a distância (BAUMAN, 2001, p. 16). 
Isso contribui para a instituição de novos modelos e valores de legitimação da existência individual - uma dinâmica de visibilidade midiática de estar na mídia -, deixar-

se representar ou se autorrepresentar. É nessa tênue e ambígua fronteira entre o desejo de participação midiática do público no telejornal e o incentivo do constante do telejornal convocando o público a fazer parte do processo, que se orienta esta investigação.

\section{Desenvolvimento}

Segundo Mattos (1982), a origem e desenvolvimento histórico da televisão brasileira devem ser apresentados em cinco fases, a fim de que se tenha um perfil global de sua evolução. Cada etapa tem um período definido a partir de acontecimentos que, direta e indiretamente, servem como ponto de referência para o seu início. O estabelecimento de cada fase foi determinado levando-se em conta o desenvolvimento da televisão brasileira dentro de nosso contexto socioeconômico cultural. Assim sendo, temos: a) a fase elitista (1950-1964); b) a fase populista (1964-1975); c) a fase do desenvolvimento tecnológico (1975-1985); d) a fase da transição e da expansão internacional (1985-1990); e) a fase da televisão em convergência (anos 2000). A partir dessa divisão, sugere-se uma atualização com a inclusão de uma sexta fase da televisão, que se inicia nos anos 2010, como a fase da televisão multiplataforma: as redes sociais online, os aplicativos digitais, as transmissões online e os diversos processos de produção, fruição e participação do público na construção das notícias.

\section{As fases da televisão: 1950 a 2010}

$\mathrm{Na}$ fase elitista (1950-1964), quatro meses depois de ter sido inaugurada a primeira emissora de televisão do Brasil e da América do Sul - a TV Tupi Difusora de São Paulo, em 20 de janeiro de 1951 -, o empresário Assis Chateaubriand iniciava novo empreendimento na cidade do Rio de Janeiro. No dia 20 de janeiro de 1951, foi inaugurada a TV Tupi/Rio, também instalada provisoriamente nas dependências da Rádio Tamoio, nas proximidades da Praça Mauá. Além da precariedade das instalações, a nova emissora enfrentou problemas com relação à localização da sua antena/retransmissor (MATTOS, 1982; PRIOLLI, 1985). 
O grupo dos Diários Associados, com seu grupo gestor, pretendia colocar a antena da TV Tupi no Alto do Corcovado, junto à imagem do Cristo Redentor. Tal ideia encontrou forte oposição do clero local e a solução foi colocá-la no Pão de Açúcar. Apesar de todas as deficiências e improvisações, a televisão foi saudada pela imprensa escrita como sendo o novo e poderoso instrumento com que "conta nossa terra" (MATTOS, 1982; PRIOLLI, 1985). Nos dois primeiros anos de sua implantação, a televisão não passou de um brinquedo de luxo das elites do país. Isto se justifica pelo fato de, nos primeiros anos, um televisor custar três vezes mais do que a mais sofisticada radiola do mercado e um pouco menos que um carro (MATTOS, 1982; PRIOLLI, 1985).

Quando a televisão começou no Brasil, praticamente não existiam receptores. $\mathrm{O}$ total não passava de 200, mas, visando a popularizar o veículo, Chateaubriand mandou instalar alguns aparelhos em praça pública a fim de que as pessoas pudessem assistir à programação (MATTOS, 1982; PRIOLLI, 1985). Com esse breve histórico, compreendese o porquê, na fase elitista, da maioria da população não ter acesso ao meio de comunicação. A noção de público ou telespectador, à época, ainda não existia, visto que poucas pessoas tinham acesso ao aparelho de televisão.

As poucas participações do público, quando aconteciam, eram com idas presenciais às emissoras de TV, o envio de cartas e poucas ligações telefônicas, diante da dificuldade da população brasileira em adquirir tanto um aparelho televisor quanto um aparelho telefônico, ou mesmo morar em numa região ou cidade que recebesse o sinal de transmissão da programação. Conforme Ribeiro, Sacramento e Roxo (2010), os anos 1950 seriam marcados pela expansão da televisão como uma rede de imagens nas principais cidades do país: de 1955 a 1961 são inauguradas 21 novas emissoras. Em 1955, começa a funcionar a TV Itacolomi (Belo Horizonte); ao final da década, têm início a TV Piratini (Porto Alegre) e a TV Cultura (São Paulo).

A fase populista (1964-1975) representa, para a televisão e as produções telejornalísticas, o momento-chave do período ao consolidarem-se certas práticas de como fazer televisão, em contraponto ao período anterior de experimentação. Segundo Ribeiro, Sacramento e Roxo (2010, p. 59), “é nesse período também que a televisão, antes tida como artigo das elites, começa a se popularizar ao tornar-se acessível a um número 
maior de pessoas”. A maioria dos aparelhos de televisão encontrava-se no Rio de Janeiro e São Paulo, até o final dos anos 1960. É justamente na fase populista que a noção de público de televisão é formada, distinguindo-se dos demais meios de comunicação: rádio, jornal, revista, cinema e teatro.

A grade de programação das emissoras materializa a noção de público, ao orientálo na construção de uma rotina baseada em hábitos e consumos diários. Percebe-se a necessidade em criar uma "grade" que oriente a noção de público que servirá de "molde" para sua representação do cotidiano. A partir do ano de 1964, a televisão - aparelho e programação -, aparece como uma parte indissociável do cenário e da rotina familiar, ocupando um lugar de destaque na família brasileira. A grade limitava-se, a exemplo da TV Rio, ao período da manhã: das $4 \mathrm{~h}$ às $11 \mathrm{~h}$. O telejornal ocupava o horário das $7 \mathrm{~h} 55$ às 8h10, ou seja, 15 minutos de notícia intercaladas no universo de sete horas de programação. A noção de público dos profissionais de propaganda da época era de entretenimento familiar. Daí o esforço no sentido de ajustar a sua programação à rotina das necessidades diárias de lazer e de informação de uma casa (RIBEIRO; SACRAMENTO; ROXO, 2010).

Pode-se afirmar, contudo, que a participação do público no telejornalismo começa a receber contornos mais elaborados. Desde o início da televisão e do telejornalismo no Brasil, um conceito esteve sempre presente: o de mediação entre a notícia e o público. $\mathrm{O}$ lugar de mediador da sociedade prevalecerá até a era digital, quando se estabelece uma participação mais ativa do público na construção da notícia. Com isso, concluiu-se que se ganham novos contornos de colaboração na participação da audiência ativa. As ferramentas de participação do público no telejornal, no período de expansão do telejornalismo, eram por meio de cartas, contatos telefônicos, idas presenciais às emissoras de televisão ou como personagens da notícia durantes as reportagens.

Os anos se passaram e uma nova fase do desenvolvimento tecnológico (19751985) surgiu, mudando a produção na TV tradicional - era a chegada do videoteipe. Com ele, foi possível gravar, editar, transmitir e retransmitir a programação televisiva. Do $a o$ vivo ao videoteipe até à digitalização dos processos, o telejornalismo continua com praticamente as mesmas características. Para Machado (2001), 
[...] tecnicamente falando, um telejornal é composto de uma mistura de distintas fontes de imagem e som; gravações em fita, filmes, material de arquivo, fotografia, gráficos, mapas, textos, além de locução, música e ruídos. Mas, acima de tudo e fundamentalmente, o telejornal consiste de tomadas em primeiro plano enfocando pessoas que falam diretamente para a câmera (posição stand up), sejam elas jornalistas ou protagonistas: apresentadores, âncoras, correspondentes, repórteres e entrevistados (MACHADO, 2001, p. 103-104).

Com os avanços tecnológicos, o jornalismo contemporâneo mudou radicalmente. Embora a TV tradicional ainda tenha um alcance de muita expressividade, foi inevitável não passar por mais uma transformação, desta vez, uma mudança além das suas estações de operação. A televisão e o telejornalismo se consolidam como meio de comunicação de massa. A modernização dos programas jornalísticos se insere em um conjunto de transformações com a implantação de um padrão estético específico, buscando explorar novas tecnologias: câmeras mais leves, videoteipes e uma estética visual. O público no telejornalismo, contudo, verifica-se que permanecia como coparticipante dos eventos jornalísticos com mesclas de jornalismo e entretenimento.

A fase da transição e da expansão internacional (1985-1990) é marcada pela transição democrática no Brasil, após 30 anos de regime militar. A segmentação, os canais pagos, o videocassete, as primeiras experiências de interatividade e de digitalização reconfiguram o mercado televisivo. Um divisor de águas no cenário internacional. Com o desfecho da Guerra Fria, a partir da queda do Muro de Berlim, abriram-se novas perspectivas mercadológicas no Ocidente.

Um dos pontos altos nessa fase foi a expansão do mercado televisivo com a instalação dos primeiros canais por assinatura, trazendo o conceito de telejornalismo all news. Verifica-se, nesse momento, uma ruptura na hegemonia das grandes redes de TV aberta com a Lei ${ }^{0} 8.977$, de 6 de janeiro de 1995, a qual prevê que toda operadora de TV a cabo deverá dispor de seis canais de utilidade pública, assim distribuídos: um ligado à Câmara dos Deputados; outro ao Senado Federal e outro para uso partilhado entre a Assembleia Legislativa e a Câmara de Vereadores; um educativo-cultural, para ser usado pelos órgãos que lidam com a educação e cultura (BRASIL, 1995). 
Com o início dos anos 2000, e o processo de expansão da internet, a participação do público e sua interferência no fazer jornalismo torna-se mais evidente. $\mathrm{O}$ avanço no processo de digitalização alterou a forma de ver e de produzir televisão. No Brasil, a convergência digital está associada à expansão da televisão. Assim, verifica-se que as empresas de televisão começam a explorar outros canais e suportes para oferecerem seus produtos: blogs, sites, twitters e aparelhos celulares.

Nas fases quinta e sexta - de 2000 a 2010 e de 2010 até o presente -, o conceito de interatividade ${ }^{2}$ se estabelece nas relações com o público e a sua consequente audiência. Tudo isso por causa de uma nova plataforma: a internet - ambiente virtual para onde convergiram os formatos dos grandes veículos de comunicação. Com a enorme quantidade de usuários, a internet trouxe diversos benefícios para a comunicação e ainda possibilitou a participação e a interatividade do meio de comunicação com o consumidor de notícias. "As novas tecnologias da informação oferecem instantaneidade, interatividade, abrangência e liberdade" (TOURINHO, 2007, p. 21).

Os cidadãos procuram um local para debater e a televisão é um destino provável, porque sempre está disponível ao alcance do público da TV aberta ou a cabo, com uma variação de possibilidades e suportes de acesso. As emissoras têm a consciência da importância da participação do telespectador, por isso investem fortemente nas estratégias de interação, sempre disponibilizando esses espaços de participação, haja vista que quase toda a programação na TV, atualmente, permite a interação com o público. Devido às tecnologias digitais, que possibilitaram a convergência entre as mídias, o "contrato de escuta" (VERÓN, 2005, p. 276) se realiza com diversos recursos tecnológicos de informação e comunicação.

O público, ao interagir nos suportes das mídias digitais, tem a sua copresença na TV estimulada pelo uso da internet. Assim, a interatividade se apresenta como uma quase interação face a face, uma interação real midiatizada nas plataformas digitais. A relação face a face acontece num contexto de copresença; os participantes partilham do mesmo

\footnotetext{
2 Manovich (2001) considera que o termo interatividade abrange um conceito muito amplo, sendo que a interface moderna de usuário no computador já é interativa por definição, diferente das primeiras interfaces, permitindo controlar o computador em tempo real por meio da manipulação da informação que se mostra na tela por meio das representações numéricas.
} 
referencial de espaço e tempo. A riqueza das deixas simbólicas na interação aliada à copresença são as características que diferenciam esse tipo de comunicação das interações mediada e quase mediada (THOMPSON, 1995, p. 78).

O espaço do telespectador é um "dispositivo de enunciação" pelo qual opera o contrato de escuta entre o meio e o público. "No campo das mídias, comunicar hoje implica manter um laço contratual no tempo" (VERÓN, 2005, p. 276). No Quadro 1, a seguir, pode-se observar a participação do público no telejornalismo nas fases da televisão, de 1950 aos anos 2010:

Quadro 1 - participação do público no telejornalismo.

\begin{tabular}{|c|c|c|c|c|c|}
\hline Fases da TV & $\begin{array}{c}\text { Cartas/Contato } \\
\text { pessoal }\end{array}$ & $\begin{array}{l}\text { Telefone } \\
\text { Fixo }\end{array}$ & Fax & $\begin{array}{l}\text { Telefone } \\
\text { celular/ } \\
\text { Internet }\end{array}$ & $\begin{array}{l}\text { App de } \\
\text { mensagens/Redes } \\
\text { sociais }\end{array}$ \\
\hline $1950-1964$ & $\mathrm{X}$ & $\mathrm{X}$ & - & - & - \\
\hline $1964-1975$ & $\mathrm{X}$ & $\mathrm{X}$ & - & - & - \\
\hline $1975-1985$ & $\bar{X}$ & $\bar{X}$ & - & - & - \\
\hline $1985-1990$ & $\mathrm{X}$ & $\mathrm{X}$ & $\mathrm{X}$ & - & - \\
\hline $1990-2000$ & $\mathrm{X}$ & $\mathrm{X}$ & $\mathrm{X}$ & $\mathrm{X}$ & - \\
\hline $2000-2010$ & $\mathrm{X}$ & $\mathrm{X}$ & $\mathrm{X}$ & $\mathrm{X}$ & - \\
\hline 2010 - & X & X & $X$ & X & $\mathrm{X}$ \\
\hline
\end{tabular}

Fonte: autoria própria.

O Quadro 1 demonstra que a evolução tecnológica colaborou com os modos de participar do público. No início, com poucos recursos, e, mais tarde, com múltiplas formas e possibilidades. Um suporte parece onipresente em todas as fases: o telefone. Este pôde ser usado nas várias formas, desde o incentivo à participação em programas (como o Linha Direta - uma mistura de jornalismo e entretenimento) com canais de voz, aos aparelhos de pager, centrais específicas para receberem e enviarem mensagens instantâneas.

Quando se pensa em internet, as formas de interação são as mais diversas: fale conosco, blogs, mensagens via sms, aplicativos de mensagens instantâneas, aplicativos específicos para enviar imagens (fixas e em movimento) à produção de jornalismo das emissoras de televisão. Já as redes sociais online criaram espaços de interação que se estendem a mensagens escritas e faladas, em voz e vídeo. No processo, existe uma 
interação mediada pelo suporte do computador ou smartphone no envio de mensagens com uma única direção, a televisão, que está organizada para receber as participações produzidas pelos telespectadores. Contudo, faz-se necessário afirmar que esse sistema mediado pelo computador/smartphone fornece simulações de participação no processo comunicativo. O suporte, como tecnologia mediadora, atua no sentido de transparecer essa representação simbólica de situações interativas. O fenômeno dessa ação estimula a experiência simulada de participação, que funciona como um mecanismo auxiliar no processo de interação do público com a televisão (CAJAZEIRA, 2014).

Para haver maior clareza quanto à participação do público, desenvolveu-se a conceituação baseada nos estudos de audiência no telejornalismo tratados pelo pesquisador (CAJAZEIRA, 2014, p. 32) com três principais formas de interação: a) direta, b) indireta e c) simultânea. Esses canais se apresentam como geradores de dados de audiência (share) para os telejornais nas redes sociais online.

1. Direta - São dois os principais canais de interação direta do público com o telejornal na internet:

a) Fale Conosco - localizado nos sites das emissoras de TV e destinado ao atendimento por e-mail, por meio do qual o público pode encaminhar qualquer tipo de solicitação, sugestão ou dúvida a ser respondida pelo departamento de Jornalismo. O e-mail do público tem como destinatário o departamento de Jornalismo das emissoras de televisão e pode ser aberto a conhecimento do público ou não, dependendo do interesse jornalístico dos editores dos telejornais na sua utilização.

b) Redes Sociais - o uso desse canal de comunicação possibilita estreitar as relações entre os atores mediante um ambiente midiático capaz de publicar conteúdos próprios dos interagentes na forma de opiniões e comentários. Todo o canal, nesse formato, é monitorado por um moderador, profissional especializado em mídias sociais e designado pela empresa de comunicação para exercer essa função. Ele controla e filtra as participações do público/internauta. A moderação procura avaliar a qualidade das interações no ambiente midiático do telejornal na rede. No caso do telejornal, o sistema utilizado no recebimento desse tipo de mensagem se 
apresenta como um canal interativo de fluxo contínuo e imediato, que filtra os assuntos de interesses do público e os encaminha ao departamento de Jornalismo das emissoras de TV.

2. Indireta - essa participação acontece pela ação direta do público do telejornal que partilha e/ou publica o conteúdo jornalístico veiculado pela TV no ciberespaço: $b \operatorname{logs}$, sites e redes sociais online. Não há mediação do telejornal nesse ato comunicativo, que se estrutura pela tecnologia digital. Isso resulta na midiatização do conteúdo jornalístico em outros espaços públicos, que podem gerar, caso haja participação, novas audiências (share). A participação do público contribui na redefinição da abrangência do conteúdo jornalístico extratelevisão. Com isso, aumenta-se a visibilidade da unidade semântica (reportagens e entrevistas), por meio da sua visualidade. As relações são, por vezes, unilaterais, apenas o público partilha dos comentários, sem a participação da TV.

3. Simultânea - Ocorre quando inclui a participação na transmissão direta (ao vivo) ou assíncrônica (gravada) de programas noticiosos. Alguns programas televisivos disponibilizam ao seu público várias possibilidades de participação. São serviços de contato com o telespectador: Fale Conosco, comunicação via sms, participação do público via "fala povo", participação telefônica com pagamento por minuto falado na ligação, e-mails e redes sociais online. O emissor (TV) converge os conteúdos na plataforma das redes sociais e possibilita ao receptor agir como um emissor, caso partilhe e interaja com o conteúdo. Essa ação evidencia-se como um dos princípios da interatividade, que, nesta investigação empírica, verificamos não ocorrer com frequência nas relações entre a TV e o público.

\section{Procedimentos metodológicos}

O Jornal Nacional (JN) é um telejornal brasileiro exibido de segunda a sábado, das $20 \mathrm{~h} 30$ até as $21 \mathrm{~h} 15$, pela TV Globo. Atualmente, é o noticioso de TV com maior audiência dentro do país e vem carregando esse posto desde a origem, no ano de 1969, conforme pode-se observar na Tabela 1 logo a seguir: 
Tabela 1 - Audiência do Jornal Nacional entre janeiro e maio de 2020.

\begin{tabular}{|c|c|}
\hline Período & Audiência \\
\hline $13 / 01$ a $19 / 01$ & 29,1 \\
\hline $20 / 01$ a $26 / 01$ & 30,1 \\
\hline $27 / 01$ a $02 / 02$ & 28,4 \\
\hline $03 / 02$ a $09 / 02$ & 28,2 \\
\hline $10 / 02$ a $16 / 02$ & 29,8 \\
\hline $17 / 02$ a $23 / 02$ & 28,3 \\
\hline $24 / 02$ a $01 / 03$ & 28,5 \\
\hline $02 / 03$ a $09 / 03$ & 29,0 \\
\hline $10 / 03$ a $15 / 03$ & 29,3 \\
\hline $16 / 03$ a $22 / 03$ & 34,2 \\
\hline $23 / 03$ a $29 / 03$ & 33,1 \\
\hline $30 / 03$ a $05 / 04$ & 30,3 \\
\hline $06 / 04$ a $12 / 04$ & 29,1 \\
\hline $13 / 04$ a $19 / 04$ & 29,7 \\
\hline $20 / 04$ a $26 / 04$ & 30,2 \\
\hline $27 / 04$ a $03 / 05$ & 29,4 \\
\hline $04 / 05$ a $10 / 05$ & 29,2 \\
\hline $11 / 05$ a $17 / 05$ & 29,3 \\
\hline
\end{tabular}

Fonte: Kantar Ibope (2020).

Para cada 1 ponto de audiência são considerados, agora, 70.559 mil domicílios. Na contagem por pessoas, 1 ponto de audiência equivale a 199.309. O Jornal Nacional É apresentado pelos jornalistas Willian Bonner e Renata Vasconcellos (Figura 1) que, além de âncoras, são os editores-chefes do telejornal.

Figura 1 - Âncoras do Jornal Nacional Willian Bonner e Renata Vasconcellos na bancada do JN

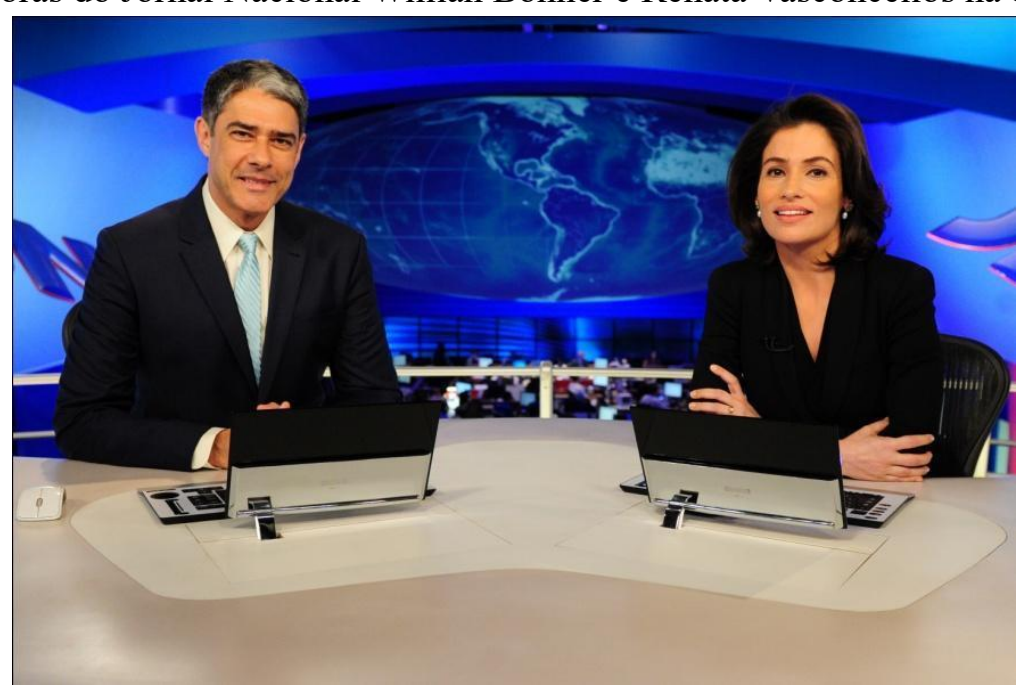

Fonte: g1.globo.com.

ISSN: $2238-5126$ 
Com toda a contingência de audiência perante o noticioso, o Jornal Nacional encontrou a necessidade de expandir sua exibição por meio das novas mídias, de forma que foi um dos telejornais pioneiros no uso de cibermeios para disponibilizar o seu conteúdo na internet. Desta forma, o JN possui um site oficial incorporado ao site central do jornalismo da TV Globo, o G1, uma fanpage na rede social Facebook, um perfil na rede social Twitter e um perfil no aplicativo para plataformas móveis Instagram. O site oficial do JN, a fanpage no Facebook e o Twitter são os objetos de estudo desta presente pesquisa. Existem ainda os aplicativos do Globo Play, que possibilitam a audiência enviar sugestões de temas.

Figura 2 - Aspecto do site https://g1.globo.com/jornal-nacional/

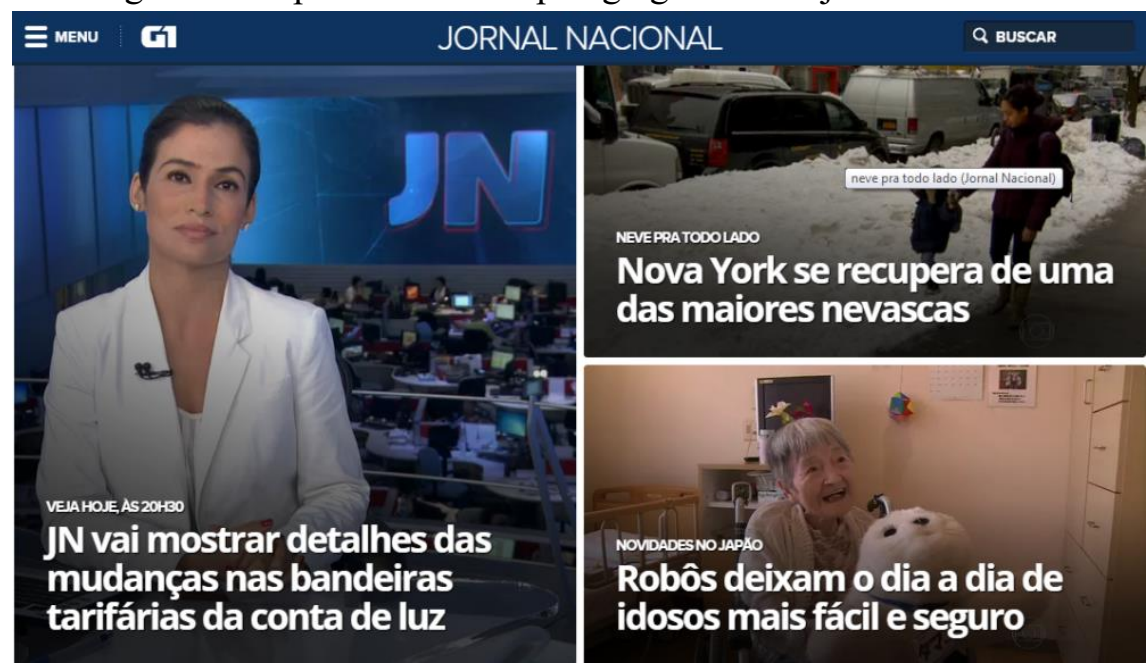

Fonte: https://g1.globo.com/jornal-nacional/

Tais espaços do Jornal Nacional na internet possibilitam que o público tenha um acesso mais fácil à programação. $\mathrm{O}$ que muitas vezes não pode ser assistido ao vivo na televisão, pode ser acessado posteriormente pela internet, a qualquer momento e em qualquer lugar. Neste trabalho, optou-se por delimitar a análise sobre a interatividade. Assim sendo, buscou-se observar como esta característica se apresenta dentro do site, da fanpage e do twitter do Jornal Nacional. Na interatividade, o objetivo maior foi visualizar o novo processo de participação do público junto ao jornal, ou seja, enxergar como os telespectadores têm, com o uso das mídias digitais do Jornal Nacional, a sua capacidade 
de emitir opinião e realizar o feedback da notícia potencializada por meio de uma maior gama de canais para a realização desta empreitada.

\section{Instrumento de coleta de dados}

Foram utilizados para a análise das relações de interatividade modelos de fichas oriundos da obra organizada por Palácios (2011). Nesse livro técnico, que disponibiliza ferramentas para esse tipo de pesquisa, encontra-se a ficha de análise da interatividade em cibermeios, elaborada pelos autores Koldo Meso, Graciela Natansohn, Bella Palomo e Cláudia Quadros. Tal modelo foi adaptado para a presente pesquisa e resultou na ficha que foi aplicada no período de análise de $1^{\circ}$. de maio a $1^{\circ}$. de junho de 2019 .

Quadro 2 - Ficha para análise de interatividade em cibermeios.

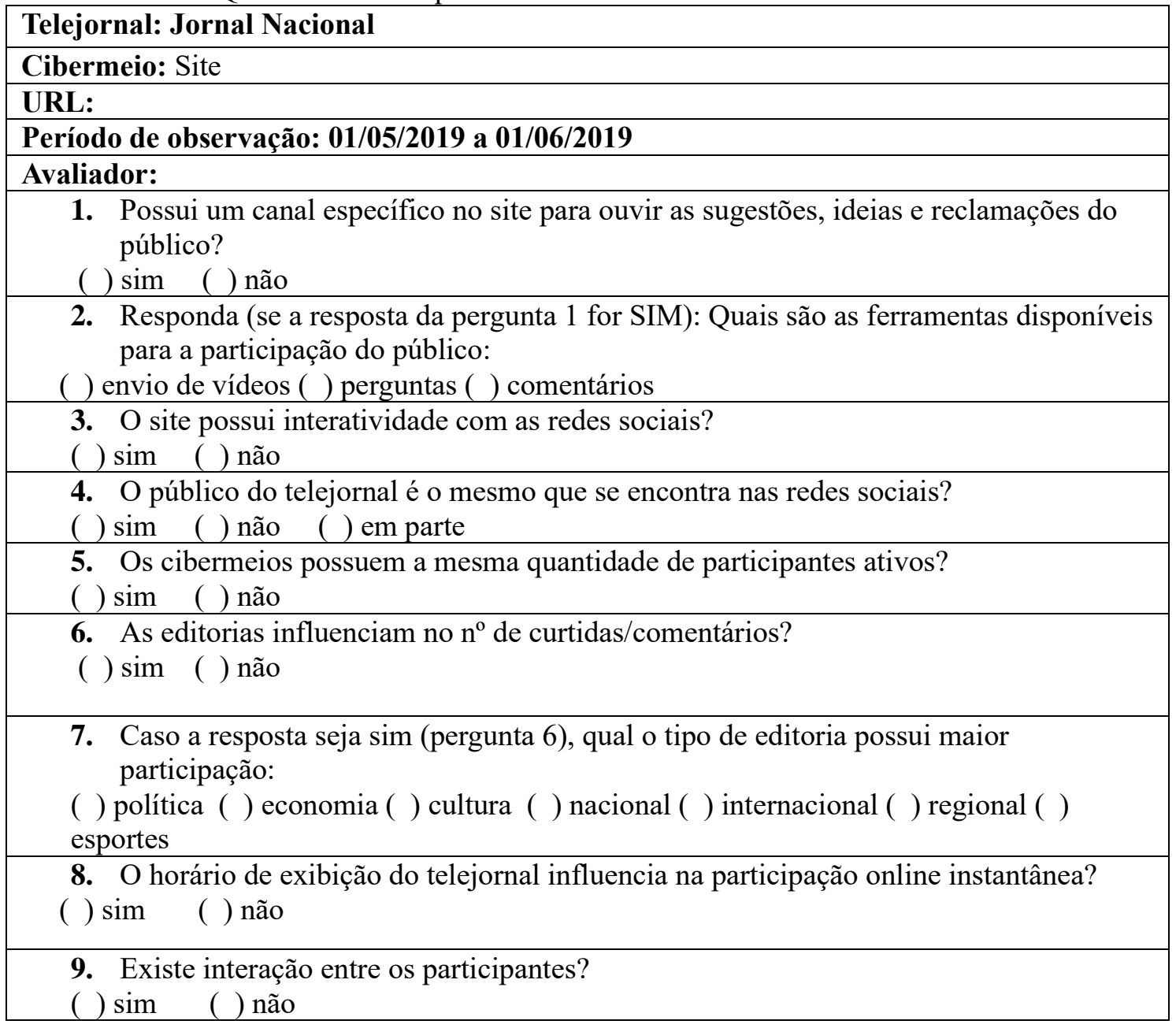


10. O cibermeio utiliza algum recurso que visa perceber diretamente as opiniões do
público?

( ) $\operatorname{sim} \quad$ ( ) não

Se SIM, qual:

( ) enquete ( ) fórum ( ) concurso ( ) chat

11. São usados recursos para estimular a participação do público?

( ) $\operatorname{sim}$ ( ) não

Fonte: Palacios (2014), adaptado pela autoria.

\section{Análise de interpretação dos dados}

No período de dois meses de aplicação da ficha (01/05 a 01/06/2019) - justificado devido à complexidade dos cibermeios e à consequente necessidade de um acompanhamento e observação mais prolongados -, observaram-se as características de interatividade presentes nos cibermeios, e, após a compilação de dados e anotações, pôdese preencher as fichas. Para cada cibermeio, houve a aplicação da ficha, totalizando o número de três fichas preenchidas.

O site oficial do Jornal Nacional é um cibermeio produzido para funcionar a partir da participação do público. Os usuários podem comentar as matérias, que são disponibilizadas por meio de um texto, seguido por um vídeo da reportagem que foi ao ar pelo telejornal na televisão. Dessa forma, existe um espaço específico na parte de baixo da tela, quando o texto acaba, para armazenar os comentários e também para enviar $e$ mails diretamente para a redação do telejornal. Além disso, um link permite que os usuários enviem sua própria notícia para o site, disponibilizando uma página específica com um espaço para pôr um título, outro para um subtítulo e um terceiro para o texto do internauta. Para completar, os internautas têm um espaço específico para o envio de imagens e vídeos, por outro link de apoio.

Concomitantemente a esses elementos, a lógica de participação no site do Jornal Nacional funciona de acordo com um interessante sistema de convergência para as redes sociais. Isso porque, em todas as matérias que são disponibilizadas no site e em todos os comentários, existem ícones de compartilhamento de conteúdo para as redes sociais, como o Facebook e o Twitter. Assim, os usuários podem propagar os conteúdos rapidamente, e de forma prática, para esses outros espaços dentro da web. 
A editoria nacional, ou seja, a temática que aborda notícias diversas de repercussão para todo o Brasil, é a que possui a maior participação do público dentro do site, a partir do número de comentários presentes. Tal fator, em parte por ser o tipo de conteúdo que é mais disponibilizado dentro do cibermeio, tornando esta constatação uma consequência óbvia. As editorias nacional e internacional foram as que tiveram o maior número de matérias veiculadas durante o período de observação da pesquisa e obtiveram uma maior participação do público.

\section{Considerações finais}

O objetivo principal deste estudo foi analisar a lógica de participação do público no telejornalismo brasileiro. A investigação partiu de dois experimentos empíricos: a) revisão bibliográfica dos processos de participação do público de 1950 até os anos 2010; b) aplicação de uma ficha de análise de cibermeio adaptada à interatividade no telejornalismo, a fim de verificar as formas de participação e interação do público no Jornal Nacional da TV Globo.

A maior evidência identificada nas postagens ou publicações não foi a única razão para uma maior ou menor participação dos usuários, haja vista que diversos fatores subjetivos também entraram na análise, como gostos ou preferências individuais de cada um que acessa os cibermeios. Como se pode observar, as pautas nacionais foram as que tiveram uma maior interatividade com o público no que se refere a comentários. Além dos aspectos relacionados à participação do público em relação às editorias, outro fator de interatividade importante é a participação do público de acordo com a exibição ao vivo do Jornal Nacional na televisão. No site do $\mathrm{JN}$ as postagens são feitas após a exibição do telejornal.

Portanto, o Jornal Nacional na atualidade é um produto híbrido, concebido para várias mídias, e que fortalece sua atuação perante o público ao apresentar multiformatações disponíveis para multitelas. Enfim, o grande questionamento a ser feito com a revolução das mídias digitais no telejornalismo não é o que deixa de existir ou passa a ser descartável, mas sim o que se transforma para uma estrutura mais complexa, volátil e, por isso mesmo, inovadora. 


\section{Referências}

BAUMAN, Zigmunt. Modernidade líquida. Rio de Janeiro: Jorge Zahar, 2001.

BRASIL. Lei $\mathbf{n}^{\mathbf{0}}$ 8.977, de 6 de janeiro de 1995. Dispõe sobre o serviço de TV a Cabo e dá outras providências. Brasília, DF, jan. 1995. Disponível em: http://www.planalto.gov.br/ccivil_03/leis/18977.html. Acesso em: 8 jun. 2019.

CAJAZEIRA, Paulo Eduardo Silva Lins. O jornalismo colaborativo no telejornal com as novas mídias digitais. Covilhã: BOCC, 2014.

DAYAN, Daniel. Televisão, o quase público. Lisboa: Livros Horizonte, 2006.

JORNAL NACIONAL. Facebook. Disponível em: https://www.facebook.com/ JornalNacional?fref=ts. Acesso em: 01 maio 2019 a 01 jun. 2019.

JORNAL NACIONAL. Site. Disponível em: https://g1.globo.com/jornal-nacional/. Acesso em: 01 de maio 2019 a 01 de jun. 2019.

JORNAL NACIONAL. Twitter. Disponível em: https://twitter.com/jornalnacional?lang =pt. Acesso em: 01 maio 2019 a 01 jun. 2019.

MACHADO, Arlindo. Máquina e imaginário: o desafio das poéticas tecnológicas. São Paulo: Edusp, 2001.

MANOVICH, Lev. The language of new media. Cambridge: The Mit Press, 2001.

MATTOS, Sergio. O impacto da Revolução de 1964 no desenvolvimento da televisão. Cadernos do INTERCOM. São Paulo, ano 1, n. 2, p. 29-43, 1982.

MESO, Koldo; NATANSOHN, Graciela; PALOMO, Bella; QUADROS, Cláudia. Ferramentas para análise de interatividade em cibermeios. In: PALACIOS, Marcos (org.). Ferramentas para análise de qualidade no ciberjornalismo. Covilhã, Portugal: UBI/ LabCom, Livros LabCom, 2011, p. 51-80. v. 1 Modelos.

PALÁCIOS, Marcos. Ferramentas para análise de qualidade no ciberjornalismo. Covilhã, Portugal: UBI/ LabCom, Livros LabCom, 2011. v. 1 Modelos.

PRIOLLI, Gabriel. A tela pequena no Brasil grande. In: BARBOSA LIMA, Fernando; PRIOLLI, Gabriel; MACHADO, Arlindo. Televisão e vídeo, Rio de Janeiro: Jorge Zahar, 1985, p. 20-43. 
RIBEIRO, Ana Paula Goulart; SACRAMENTO, Igor; ROXO, Marco. História da televisão no Brasil: do início aos dias de hoje. São Paulo: Contexto, 2010.

TOURINHO, Carlos. Jornalismo regional e optativo na Rede Globo: Programa Painel de Domingo. Vitória: Espaço Livros, 2007.

VERÓN, Eliseo. Construir el acontecimento. Barcelona: Gedisa, 1995.

Submetido em: 21.06.2019

Aprovado em: 30.06 .2020 